\title{
DUTCH BOOKS AND LOGICAL FORM
}

\author{
Joel Pust \\ Department of Philosophy \\ University of Delaware \\ Newark, DE 19716 \\ U.S.A. \\ Email: jpust@udel.edu
}

\begin{abstract}
Dutch Book Arguments (DBAs) have been invoked to support various alleged requirements of rationality. Some are plausible: probabilism and conditionalization. Others may be less so: credal transparency and reflection. Anna Mahtani has argued for a new understanding of DBAs which, she claims, allows us to keep the DBAs for probabilism (and perhaps conditionalization) and reject the DBAs for credal transparency and reflection. I argue that Mahtani's new account fails as (a) it does not support highly plausible requirements of rational coherence and (b) it does not succeed in undermining the DBAs for credal transparency or reflection.
\end{abstract}




\section{DUTCH BOOKS AND LOGICAL FORM}

\section{Dutch Books: Good and Bad}

Dutch Book Arguments (DBAs) have been invoked to support various intuitively plausible requirements of rationality such as the synchronic requirement of probabilism (the requirement that one's credences obey the probability calculus) and the diachronic requirement of conditionalization (the requirement that one's posterior credences, upon learning a proposition, equal one's prior credences conditional on the proposition learned). They have also, however, been invoked in support of allegedly more dubious requirements such as synchronic credal transparency (the requirement of certainty regarding one's current credences) and the diachronic requirement of reflection (the requirement that one's current credence in a proposition, conditional on one's future credence in that proposition being $n$, equal $n)$.

Recently, Anna Mahtani (2015) has argued for an interesting new understanding of DBAs on which, she claims, "we get to keep the DBAs we want and reject those that we don't" (522). More precisely, she claims that her new account yields a DBA for probablism but does not yield a DBA for credal transparency nor, perhaps more significantly, for reflection. (She remains neutral on the status of the DBA for conditionalization, given her new understanding). The core of her proposal is as follows: Instead of requiring the bookie 
to compose her book of bets given only access (at suitable times) to the agent's credence function (a mapping from propositions to degrees of confidence), as is standard in DBAs, it requires the bookie to compose her book of bets given access only to a different function $-\mathrm{a}$ mapping from a representation of the logical form of propositions to degrees of confidence. The bookie, on this new account, must make her book against the agent given suitable access only to the logical form of the propositions in which the agent invests confidence and the degree of confidence the agent invests in those propositions.

I shall argue here that Mahtani's proposal fails as (a) it does not support highly plausible requirements of rational coherence and (b) it does not, even setting aside my first objection, succeed in undermining the requirement of credal transparency. The first problem results from the fact that ideal rationality requires more than coherence as defined relative to a suitable logic. The second problem results from the fact that the logical form of credences in credences is plausibly sufficiently rich to guarantee that mere knowledge of the logical form of the agent's credences will suffice to enable the bookie to guarantee a loss for any agent failing credal transparency. Though I shall consider only the synchronic case of credal transparency in detail, if my second objection is correct, it will also follow that Mahtani's new account will not allow us to reject the diachronic DBA for reflection whilst possibly retaining the diachronic DBA for conditionalization. This is because her account 
gives exactly the same reason for rejecting the DBA for credal transparency as for rejecting the DBA for reflection.

\section{Simple Books and Credal Transparency}

Consider Alan, who has a credence of 0.6 in the proposition that all whales are mammals and a credence of 0.5 in the proposition that not all whales are mammals. Alan violates a consequence of the probability calculus,

$$
\mathrm{P}_{s, t}(\mathrm{H})=\mathrm{x} \text { iff } \mathrm{P}_{s, t}(\sim \mathrm{H})=1-\mathrm{x}
$$

Assuming that Alan's credences justify his accepting bets in the standard way, a bookie who knew only Alan's credence function could offer Alan the following two bets which Alan would (we here assume along with other proponents of DBAs) regard as fair but which would, no matter how the world turned out, guarantee that Alan loses money and so has been "Dutch Booked:"

\section{BET A}

\begin{tabular}{|l|l|}
\hline $\begin{array}{l}\text { All whales are } \\
\text { mammals. }\end{array}$ & $\$ 1-\$ 0.6$ \\
\hline $\begin{array}{l}\text { Not all whales } \\
\text { are mammals }\end{array}$ & $-\$ 0.6$ \\
\hline
\end{tabular}

BET B

\begin{tabular}{|l|l|}
\hline $\begin{array}{l}\text { All whales are } \\
\text { mammals }\end{array}$ & $-\$ 0.5$ \\
\hline $\begin{array}{l}\text { Not all whales } \\
\text { are mammals }\end{array}$ & $\$ 1-\$ 0.5$ \\
\hline
\end{tabular}


Bet A on 'all whales are mammals' where Alan stakes $\$ 0.6$ and wins $\$ 1$ if all whales are mammals is fair given Alan's credence in 'all whales are mammals.' Bet B on 'not all whales are mammals' where Alan stakes $\$ 0.5$ and wins $\$ 1$ if not all whales are mammals is fair given his credence in 'not all whales are mammals.' However, he is then committed to regarding as fair a set of bets which, if placed and settled, guarantee that he will end up poorer by $\$ 0.1$ regardless of whether 'all whales are mammals' is true or not. This, it is plausibly claimed by proponents of DBAs, shows that such a set of credences is irrational. That we can give such arguments for each of the axioms of the probability calculus is likewise plausibly thought to show that violating such axioms is irrational and so to justify probabilism.

Now, consider Charlotte, who has a credence of 0.75 that London is a capital city but is not certain that her current credence in that claim is 0.75 . Let us suppose that her credence that her credence that London is a capital city is 0.75 is 0.8 but that she is coherent and so her credence that her credence that London is a capital city is not 0.75 is 0.2 . Nonetheless, she violates,

CREDAL TRANSPARENCY: $\mathrm{P}_{s, t}(\mathrm{H})=\mathrm{x}$ only if $\mathrm{P}_{s, t}\left(\mathrm{P}_{s, t}(\mathrm{H})=\mathrm{x}\right)=1$ 
Moreover, it seems that a DBA can be given against anyone who, like Charlotte, violates CREDAL TRANSPARENCY, for the bookie, knowing Charlotte's credence function, can offer her the following bet:

\section{BET C}

\begin{tabular}{|l|l|}
\hline $\begin{array}{l}\text { My current credence that } \\
\text { London is a capital city is } \\
\text { not } 0.75 .\end{array}$ & $\$ 1-\$ 0.2$ \\
\hline $\begin{array}{l}\text { My current credence that } \\
\text { London is a capital city is } \\
0.75 .\end{array}$ & $-\$ 0.2$ \\
\hline
\end{tabular}

Bet $\mathrm{C}$ would have Charlotte staking $\$ 0.2$ on 'my current credence that London is a capital city is not $0.75^{\prime}$ and winning $\$ 1$ if that is so. Charlotte will regard Bet $\mathrm{C}$ as fair, given that her credence in 'my current credence that London is a capital city is not 0.75 ' is 0.2 . As the bookie, knowing only Charlotte's credence function, knows that Charlotte's current credence in 'London is a capital city' is in fact 0.75 , she can guarantee that Charlotte will lose 
money with Bet $\mathrm{C}$ no matter how the non-credal world turns out. ${ }^{1}$ Hence, it seems that Charlotte's credences are incoherent or irrational just as are Alan's in virtue justifying the acceptance of a set of bets guaranteed to be a losing set. Mahtani claims that the sense in which a loss in guaranteed here is that "it is necessary that if Alan [or Charlotte] accepts the bets as fair, then he [she] will lose money on them" (523). Put another way, Alan and Charlotte are both such that there is no possible world in which they regard their respective sets of bets as fair but those bets are not a losing set of bets.

\section{Mahtani's New Account of DBAs}

Mahtani regards CREDAL TRANSPARENCY as clearly mistaken, claiming that an agent can be coherent without being "certain of every true claim about her own credence function" (524). However, Mahtani's argument for this claim is not convincing. She suggests that coherence does not require that an agent "be certain of every true claim - and that seems to include claims about herself. An agent can be coherent without being certain what her his or her blood group is, or whether (s)he is in love, and it seems similarly she can

\footnotetext{
1 See Milne (1991) for a more careful and complicated account on which Charlotte would also be offered two bets on 'London is a capital city' that cancel each other out.
} 
be coherent without being certain of every true claim about her own credence function" (524).

The suggested analogy here seems quite strained as not all facts about oneself are reasonably thought to be introspectable or, more importantly, to be the locus of evaluation when one's epistemic rationality is at stake. My blood group is not epistemically evaluable nor is it the sort of thing even prima facie discernable by introspection. Indeed, Mahtani herself seems vaguely aware of this disanalogy when she notes that it "may be tempting to think there should be some sort of fit between a coherent agent's credence function and the credence function (s)he thinks she has" (525) but she neglects to notice that there is no corresponding temptation whatsoever to think rationality alone requires a fit between one's blood group and one's credences regarding one's blood group.

Regardless of the plausibility of her argument against CREDAL TRANSPARENCY, Mahtani is not alone in thinking that it is false and that an understanding of DBAs, such as the standard one above, on which it is supported, is thereby shown to be mistaken. ${ }^{2}$ She

2 See Christensen (2007). See also Williamson's (2008) technical anti-luminosity arguments with respect to evidential probability. Of course, much more attention has been focused on diachronic principles, especially on how to plausibly distinguish the 
argues, then, for a new understanding of DBAs on which the argument for CREDAL TRANSPARENCY is blocked but, as noted above, the argument for probabilism goes through. On her new account, the bookie has access only a function from the logical form of the propositions in which the agent has some credence to her numerical degree of belief. The bookie is "sure of the meaning of the logical terms and he understands the structure of the sentences, but he does not know what the subject specific terms mean" (525-526). If, just knowing the logical form of the propositions in the agent's credence function, he can produce bets which the agent would accept as fair and which, no matter the interpretation of the statements would result in a loss, it follows that the agent is incoherent. So, "an agent is shown to be incoherent [in the relevant sense] only if some book of bets that the agent accepts as fair will lose the agent money under any interpretation of the claims in that book of bets" (526).

Crucially, this new understanding of DBAs is alleged to preserve a DBA for probabilism. Recall Alan, who has a credence of 0.6 in the proposition that all whales are mammals and a credence of 0.5 in the proposition that not all whales are mammals. Mahtani regards these two claims as having the logical form of ' $W$ ' and ' $\sim W$,' respectively.

DBA for the plausible principle of conditionalization from the DBA for the implausible principle of reflection. 
On the new account of DBAs, the bookie does not know what ' $W$ ' means as it is a subjectspecific rather than logical term, but, given his understanding of the logical form of the two claims, he can still construct a book which Alan will regard as fair and which is guaranteed to lose money. No matter what the meaning of ' $W$ ' is, the bookie can know that the credences Alan has in the propositions represented by ' $W$ ' and ' $W$ ' are credences in two contradictory propositions and will commit him to the following set of losing bets, structurally identical to those considered earlier:

BET A

\begin{tabular}{|l|l|}
\hline $\mathrm{W}$ & $\$ 1-\$ 0.6$ \\
\hline$\sim \mathrm{W}$ & $-\$ 0.6$ \\
\hline
\end{tabular}

BET B

\begin{tabular}{|l|l|}
\hline $\mathrm{W}$ & $-\$ 0.5$ \\
\hline$\sim \mathrm{W}$ & $\$ 1-\$ 0.5$ \\
\hline
\end{tabular}

Notice that Alan's vulnerability to a book remains even if we regard the claims in question has having a logical form better captured by predicate rather than propositional logic, such as $(\forall x)(\mathrm{Wx} \supset \mathrm{Mx})$ and $\sim(\forall x)(\mathrm{Wx} \supset \mathrm{Mx})$. That this is a better representation of the logical form of the propositions at issue is implicit in Mahtani's suggestion that the bookie does not know whether 'all whales are mammals' means that all whales are mammals or 
that all fish are pencils. Still, the bookie can know that they are logically contradictory given merely knowledge of their logical form.

Turning to the DBA for CREDAL TRANSPARENCY, Mahtani writes, "It is not obvious what the logical form of 'Charlotte's credence in L [London is a capital city] is $0.75^{\prime}$. . is. Perhaps the logical form of this sentence is just $\mathrm{Pa} \ldots$ Or perhaps the logical form is $\mathrm{Pab}$ - or perhaps it has some other more complex logical form. In any case, we can focus on an interpretation under which all the terms have their actual meanings except for the term 'credence' which means 'half credence'”' (526-527), where one's half-credence in P is half of one's credence in P. On this interpretation, the sentence 'Charlotte's credence in L is 0.75 ' claims that Charlotte's half-credence in $\mathrm{L}$ is 0.75 and the sentence is false. So, it isn't true that the bookie can know, just by knowing the logical form of the propositions in Charlotte's credence function, that the aforementioned sentence is true and so it isn't true that Bet C can be known by the bookie to result in a guaranteed loss. The desirable result, according to Mahtani, is that her account of DBAs allows us to retain the DBA for probabilism while rejecting the DBA for CREDAL TRANSPARENCY. Moreover, as the DBA for the diachronic version of the reflection principle also features possible wagers on claims about the agent's credences, it is "decisively ruled out" (535), and for reasons have nothing to do with the diachronic nature of the argument. Hence, we may leave open the possibility that the diachronic DBA for conditionalization is sound. 


\section{Two Problems with Mahtani's Proposal}

As is sometimes noted, versions of probabilism differ with respect to their formulation of the requirement that a rational agent have a credence of 1 in some propositions (and so also with respect to their formulation of finite additivity). Frequently, the relevant normalization axiom requires that one have a probability of 1 for all truths of propositional logic. However, this is sometimes replaced with a requirement that one have probability of 1 for all logical truths. This latter appears to be the conception with which Mahtani is working in supposing that the bookie has access only to a mapping from the logical form of propositions to the agent's credence values. Hence, it seems clear she is making two assumptions:

[A1] Logical truths exhaust the propositions to which an agent must, on pain of irrationality, assign a probability of 1 . In other words, the normalization and finite additivity axioms of the probability axioms require that (i) if A is a logical truth, then $\mathrm{P}(\mathrm{A})=1$, and (ii) if $\mathrm{A}$ and $\mathrm{B}$ are logically incompatible, then $\mathrm{P}(\mathrm{A} \vee \mathrm{B})=\mathrm{P}(\mathrm{A})+\mathrm{P}(\mathrm{B})$. 
[A2] Knowledge of the logical form of the set of propositions in an agent's credence function will not suffice to enable a bookie to make a book against an agent who violates CREDAL TRANSPARENCY.

I shall argue that these assumptions are both mistaken. ${ }^{3}$

Here are some propositions in which rationality plausibly requires certainty or propositional schema, instances of which require certain opinion by rational agents:

[1] If $P$ is necessary, then $P$ is possible.

[2] If $\mathrm{S}$ knows that $\mathrm{P}$, then $\mathrm{P}$.

[3] If $\Phi$ is obligatory, then $\Phi$ is permissible.

[4] $\mathrm{P}_{s, t}(\mathrm{H})=\mathrm{x}$ iff $\mathrm{P}_{s, t}(\sim \mathrm{H})=1-\mathrm{x}$.

[5] I exist.

[6] If actually $\mathrm{P}$, then $\mathrm{P}$.

[7] If $x$ is taller than $y$ and $y$ is taller than $z$, then $x$ is taller than $z$.

[8] Nothing is red and green all over.

3 Though Mahtani is certainly not the only one to make the erroneous first assumption. 
None of these propositions is, however, a truth of standard propositional or predicate logic. Insofar as it is plausible that ideal rationality requires certainty in at least these (and similar) propositions, a version of probabilism which restricted its certainty requirement to predicate logic with equality is mistaken. Indeed, an agent who holds that some action is obligatory but not permissible or that she doesn't exist seems just as clearly incoherent as Alan.

Of course [1] - [3] are logical truths of standard modal, deontic and epistemic logics, [4] is a (putative) truth of the logic of credence, [5] is a truth of indexical logic (Kaplan 1978), and [6] is a truth of modal logic with an actuality operator. Mahtani might, then, take an expansive view of logical truth and thereby accommodate [1] - [6]. However, [7] and [8] and similar propositions would not be accommodated thereby even though, for example, an agent with a credence of 0.4 in ' $x$ is taller than $y$ and $y$ is taller than $z^{\prime}$ but a credence of 0.2 in ' $x$ is taller than $y$ ' would be as clearly incoherent as an agent who violated one of [1] - [6].

Though some might be tempted by the observation that [7] and [8] should be certain to require that rational agents have a probability of 1 for all necessary truths, this would be a mistake. One is not required by mere rationality to be certain of a posteriori necessary truths such as Water is H20 or Cicero is Tully. Moreover, one is required to be certain of [5] and [6] even though they are not necessary truths (the logics in question failing the necessitation rule). These observations suggest that the proper understanding of DBAs is that they reveal a rational failure in one's system of credences which is discernable independent of a posteriori 
information about the world outside one's credences. As we have seen, however, some such failures of rationality will not be revealed to a bookie who has knowledge merely of the predicate-logical form of the propositions in which one invests credence. While this may be partly ameliorated by allow a richer notion of logical form, depending on how many of [1] - [6] (and similar claims) we take to be included in the scope of logic, it cannot be entirely so. Hence, Mahtani's new account is not a plausible account of the force of Dutch Book arguments for rationality constraints and assumption [A1] is false. This is, I think, enough to justify rejecting her proposal.

Turning to [A2], I take it that it is clear that Mahtani's argument must assume that no representation of the logical form of 'Charlotte's credence that London is a capital city is 0.75 ' suffices to reveal to the bookie that it is a proposition regarding Charlotte's credence in a particular proposition where the bookie knows Charlotte's credence in that particular proposition. Of course, as Mahtani seems to recognize, it might be thought that 'Charlotte's credence that London is a capital city is $0.75^{\prime}$ has a number of logical forms, depending on the logic invoked. Its form in propositional logic is presumably simply ' $\mathrm{P}$,' in predicate logic it might be 'Pa' or 'Pab,' predicate logic with equality might yield 'Pab $=0.8$,' etc. Some hold that there is one correct logical form had by such a statement and others that there are a variety of logical forms. Either way, Mahtani's proposal is presumably that any suitable logical form will do. 
This assumption is, I believe, mistaken and also undermines her case, even setting aside the status of non-logical a priori truths. As noted above, logic is not exhausted by firstorder predicate logic with equality. There are extensions of propositional and predicate logic such as logics of metaphysical modality, epistemic logics, and, more importantly for present purposes, temporal and other indexical logics, and logics of belief and credence. There is, moreover, no clear principled reason for excluding such logics from the scope of logic proper (MacFarlane 2017). Indeed, as noted above, it would seem that Mahtani must accept that logic is not exhausted by propositional or predicate logic or be entirely unable to justify by DBA a plausible normalization axiom requiring certainty in some propositions which are not propositional or predicate logical truths. However, such a broad conception of logic vitiates Mahtani's attempt to prevent the bookie from being able to discern that an agent's second-order credences are indeed second-order credences in her first-order credences in particular propositions.

This fact, I think, will be clearer if we first attend to the fact that the relevant principle at issue is likely not, as we have assumed so far,

CREDAL TRANSPARENCY: $\mathrm{P}_{s, t}(\mathrm{H})=\mathrm{x}$ only if $\mathrm{P}_{s, t}\left(\mathrm{P}_{s, t}(\mathrm{H})=\mathrm{x}\right)=1$

but rather, 
INDEXICAL CREDAL TRANSPARENCY: $\mathrm{P}_{s, t}(\mathrm{H})=\mathrm{x}$ only if $\mathrm{P}_{s, t}\left(\mathrm{P}_{m y, n o w}(\mathrm{H})=\mathrm{x}\right)=1$.

The difference between these two claims is that the second is far more plausible as a principle of rationality as Charlotte need not know her name or the current time simply in virtue of being rational. What is more plausible is that she, and any rational agent, must have an accurate grasp of her current credences, conceived of solely as her current credences rather than as, say, Charlotte's credences on April 21st, 2019 at 3:01pm. Indeed, Bet C, above, features such doubly indexical claims.

In this light, the representation of the above noted proposition ('my current credence that London is a capital city is $0.75^{\prime}$ ) in which Charlotte's credence at time $t$ is 0.8 might be ‘ $\mathrm{P}_{m y, n o w}(\mathrm{La})=0.75$.' Proper names are not logical constants so while CREDAL TRANSPARENCY would allow for interpretations under which 'Charlotte' does not in fact designate Charlotte or some date and time term does not designate the current time, personal and temporal indexicals of the sort involved in INDEXICAL CREDAL TRANSPARENCY are plausibly logical rather than subject specific terms. So, temporal and indexical logics would allow the subscript 'my,now' as part of the logical content of the proposition at issue. Credal logics would allow the remainder of the formal representation but for the embedded proposition 'La' to count as part of the logical content of the 
proposition. Notice that we need not here take a stand on exactly which logic is correct in each of these domains. ${ }^{4}$ We need merely to hold that there are such logics and that representation of the logical form will include the elements just noted as logical constants.

This, of course, does not mean that the bookie can determine (in one sense) the identity of the embedded proposition or grasp in propia persona the proposition in which the agent takes herself to have the particular current credence. Here, however, we should recall that whatever the formula used to represent the logical form of 'London is a capital city' as it appears in the agent's credence function, the same formula must appear embedded in the formula capturing the logical form of 'I now have a degree of belief of 0.75 that London is a capital city.' 'P $\mathrm{P}_{m y, n o w}(\mathrm{La})=.75$ ' seems a plausible candidate for the logical form of Charlotte's credence that 'her current credence in 'London is a capital city' is 0.75 ,' while 'La' seems a plausible candidate for the logical form of Carlotte's credence that 'London is a capital city.' Hence, the bookie, while not knowing which proposition 'La' represents, can know that it is the same proposition represented both as a first-order object of credence and as the object of a second-order object of credence. As a result, a bookie who knows only the logical form of the propositions in the agent's credence function and her degrees of belief will know when

\footnotetext{
4 Similarly, epistemic logic represents 'S knows that $\mathrm{P}^{\prime}$ as ' $\mathrm{K}_{\mathrm{s}}(\mathrm{P})$ ' independent of which axioms, such as $\mathrm{K}_{\mathrm{s}}(\mathrm{P}) \supset \mathrm{K}_{\mathrm{s}}\left(\mathrm{K}_{\mathrm{s}}(\mathrm{P})\right)$, are endorsed.
} 
an agent's credence that she has a particular credence in a given proposition is mistaken, even while the bookie does not know in propia persona what proposition it is about which the agent has a higher-order mistaken credence. This information suffices to permit the bookie to construct a bet which he can be certain is a losing bet no matter how the extra-credal world turns out. The result is that Mahtani's alternative understanding does not, in fact, undermine the DBAs for INDEXICAL CREDAL TRANSPARENCY or reflection (in either a diachronic or synchronic form).

Perhaps an analogy involving full belief would be helpful in making my point. Consider a standard omissive version of Moore's paradox in which one believes $\mathrm{P}$ and also believes that one does not believe P. If we allow doxastic logic (logic for belief rather than degrees of belief) to count as logic, then one who has access merely to the logical form of the propositions in one's belief function (a function mapping propositions to 1 and 0 ) will be able (knowing that it is a belief function) to determine that one's beliefs are such that one is guaranteed to have a false belief. After all, the belief function will map $\mathrm{P}$ and $\sim \mathrm{B}(\mathrm{P})$ to 1 and so a bookie who knew only that she had access to the logical form of the propositions in one's belief function would be able to discern, on that basis alone, and without knowing what proposition ' $\mathrm{P}$ ' represented, that one's belief that $\sim \mathrm{B}(\mathrm{P})$ must be mistaken. My suggestion above is that something similar is true given a suitable logic for degrees of belief claims. 


\section{Conclusion}

I conclude that we should reject Mahtani's proposal. The primary notion of rationality which DBAs aim to capture is really a kind of traditional internalist epistemic rationality - a rationality the contours of which are determined by introspectable and a priori accessible truths. The narrower the bounds of logic, the more clearly Mahtani's proposal is inadequate and even with a quite capacious account of the bounds of logic, it remains unacceptable. While this problem can be remedied by returning to the old understanding of DBAs on which the bookie has access to the propositions in an agent's credence function, such an understanding would reinstate the DBA for INDEXICAL CREDAL TRANSPARENCY and, if diachronic DBAs are acceptable, reflection. The second problem shows that there is sufficient slack in the borders of logic that her proposal isn't even clearly fit for purpose. It remains plausible, even given her proposal, that a DBA can be made against an agent who violates INDEXICAL CREDAL TRANSPARENCY. Perhaps, however, this shouldn't be surprising as various normative truths regarding epistemic rationality are excellent candidates for broadly logical truths. It seems, then, that we do not yet have a way to accept a DBA for probabilism while rejecting a DBA for introspective omniscience nor to accept a DBA for conditionalization while rejecting a DBA for reflection. 


\section{$\underline{\text { References }}$}

Christensen, David. 2007. "Epistemic Self-Respect." Proceedings of the Aristotelian Society 107: 319-337.

Kaplan, David. 1978. “On the Logic of Demonstratives." Journal of Philosophical Logic 8: 8198.

Mahtani, Anna. 2015. “Dutch Books, Coherence, and Logical Consistency." Noûs 49: 522537.

MacFarlane, John, "Logical Constants," The Stanford Encyclopedia of Philosophy (Winter 2017 Edition), Edward N. Zalta (ed.), URL = <https://plato.stanford.edu/archives/win2017/entries/logical-constants/>.

Milne, Peter. 1991. "A Dilemma for Subjective Bayesians-And How to Resolve It." Philosophical Studies 62: 307-314.

Williamson, Timothy. 2008. “Why Epistemology Can't be Operationalized." In Epistemology: New Essays, Quentin Smith (ed.). New York: Oxford University Press. 